\title{
The quality of health research for young Indigenous Australians: systematic review
}

Peter S Azzopardi MB BS, MEpi, FRACP PhD Scholar' ${ }^{1}$ and

Research Fellow ${ }^{2}$

Elissa C Kennedy $\mathrm{MPH}, \mathrm{MB} B \mathrm{BS}$ Principal for Maternal and Child Health, ${ }^{3}$ and Adjunct Senior Lecturer ${ }^{4}$

George C Patton MB BS, MD, FRANZCP Professor of Adolescent Health Research

Robert Power BSc(Econ), PhD, PGCE, Principal for Harm Reduction

Robert D Roseby MB BS(Hons), FRACP Paediatrician and Director of Medical Education, ${ }^{5}$ and Former Deputy Director Adolescent Medicine

Susan M Sawye MB BS, MD, FRACP, Director and Professo of Adolescent Health

Alex D Brown BMed, MPH, PhD Senior Research Fellow, ${ }^{2}$ and Aboriginal Research

Program Leader ${ }^{6}$

I Royal Children's Hospital Centre for Adolescent Health, Murdoch Childrens Research Institute University of Melbourne Melbourne, VIC.

2 Baker IDI Heart and Diabetes Institute (Central Australia) Alice Springs, NT.

3 Burnet Institute Melbourne, VIC 4Department of Epidemiology and

Preventive Medicine Monash University, Melbourne, VIC.

5 Monash Children's Hospital, Melbourne, VIC

6 South Australian Health and Medical Research Institute Adelaide, SA.

peter.azzopardi@ rch.org.au

MJA 2013; 199: 57-63 doi: 10.5694/mjal2.11141
T here are major incentives to invest in the health of Aboriginals and Torres Strait Islanders who are adolescent or young (used interchangeably throughout this article to refer to $10-24$-year-olds). ${ }^{1}$ An estimated $31.7 \%$ of Indigenous Australians were aged 10-24 years in 2006, compared with $20.4 \%$ of the nonIndigenous population, ${ }^{2}$ and they experience an excess burden of preventable and treatable disease at a life stage when opportunities for education, employment, reproduction and independent living are at their peak. ${ }^{3}$ Births to Indigenous teenagers represent about one-fifth of all births to Australian Indigenous women; ${ }^{4}$ Indigenous young people have high rates of risk factors for the development of non-communicable diseases in adulthood (eg, obesity, tobacco-related disease); ${ }^{3}$ and the mortality gap between Indigenous and non-Indigenous Australians widens during adolescence and persists into adulthood. ${ }^{5-7}$ Indeed, improving young people's health would appear to be critical to the success of the government's National Indigenous Reform Agreement, ${ }^{8}$ particularly with regard to life expectancy, reading, writing and numeracy, secondary school completion and employment attainment. $^{9}$

Indigenous young people's health is a critical target for health system reform; however, the evidence base to inform health policy and the provision of programs to respond to specific needs remains poorly described. ${ }^{3,10}$ Measuring young people's health is complicated by a lack of agreed indicators, and the problem is compounded by the publication of adolescent health data throughout the diverse paediatric and adult literature. ${ }^{11}$ Significant deficits of Indigenous health research have also been described. ${ }^{12-14}$ However, specific research policy reform by the National Health and Medical Research Council (NHMRC) has provided guidance for improved quality of Indigenous health research, ${ }^{15,16}$ and there was an increase in the quantity of Australian Indigenous health research during 1987-2003. ${ }^{17}$

The overarching aim of our project was to establish the health status of young Indigenous Australians and identify opportunities to improve their health outcomes. The starting point was to systematically document the existing good-quality literature and the limitations of this evidence base, which we describe here. A synthesis of health outcomes and effective interventions for young Indigenous Australians is forthcoming.

\section{Methods}

We systematically searched the literature from 1 Jan 1994 1 Jan 2011 for peer-reviewed studies reporting health data

\section{Abstrac:}

Objective: To assess the extent and quality of the evidence base related to the health and wellbeing of young Indigenous Australians.

Study design: Systematic review of peer-reviewed literature; grading of quality of literature; mapping of sample characteristics and study foci.

Data sources: English language publications, 1 Jan 1994 1 Jan 2011 in MEDLINE, ERIC, CINAHL, EMBASE, ATSIhealth, PsycINFO, the Cochrane Library and the Australian Indigenous HealthInfoNet.

Study selection: Inclusion criteria were: published 1 Jan 1994 - 1 Jan 2011; original peer-reviewed research; reported data for Australian Aboriginal and Torres Strait Islanders aged 10-24 years; focused on health and wellbeing. Grading for quality included ascertainment of Indigenous status, representativeness of the sample for the target population, and quality of measures of exposure and outcome.

Data synthesis: 360 peer-reviewed publications met inclusion criteria; 90 (25\%) exclusively sampled Indigenous young people. 250 studies (69\%) were of good-quality design; 124 of these focused on health outcomes (15 of these evaluated an intervention) and 116 focused on health-risk exposure ( 26 evaluative). The methodological quality of data improved during 19942010; however, only $17 \%$ of studies focused on urban populations. A third of good-quality studies of health outcome focused on communicable diseases such as sexually transmitted infections and tuberculosis. There was good-quality data for oral health and substance use, and some data for adolescent pregnancy. Data on mental disorders, injury and cause-specific mortality were limited. Conclusions: Despite improvements, there are important gaps in the evidence base for the health of young Indigenous Australians. Our study points to the need for greater research investment in urban settings and with regard to mental disorders and injury, with a further emphasis on trials of preventive and clinical intervention.

for Indigenous Australians aged 10-24 years, identifying both descriptive data and evaluations of health interventions. ${ }^{17}$ We included studies that exclusively reported data for Indigenous young people, as well as those reporting disaggregated data (ie, studies sampling Indigenous Australians and reporting data for young people, or studies sampling young people and reporting data for Indigenous Australians). Our review process is outlined in Box 1. The Appendix (1a; online at mja.com.au) provides details of our search strategy and inclusion criteria.

\section{Critical appraisal}

We critically appraised the included studies, considering studies to be of good quality if they reliably ascertained 


\section{Systematic review process}

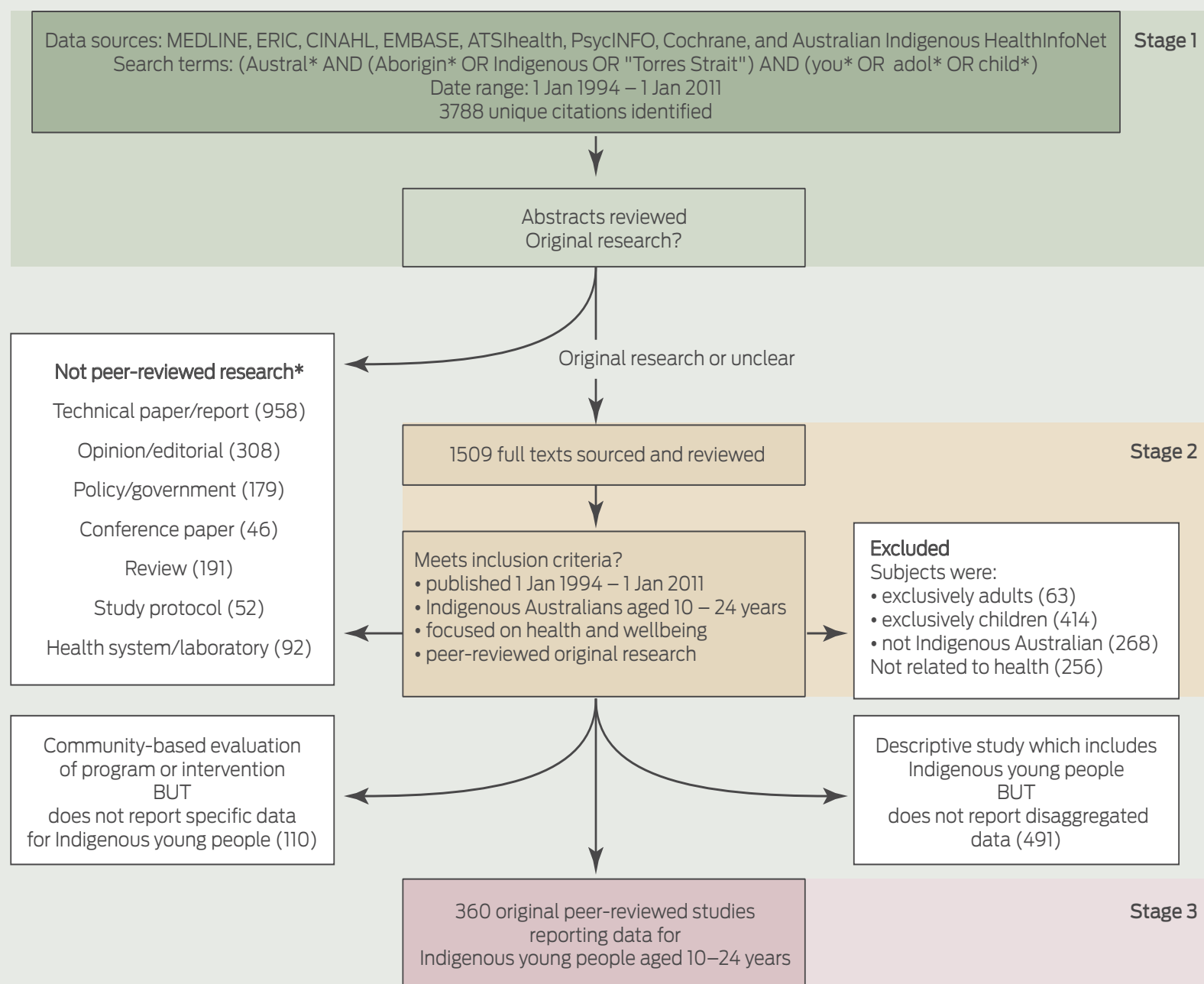

$\mathrm{ERIC}=$ Education Resources Information Center. CINAHL = Cumulative Index to Nursing and Allied Health Literature. ATSIhealth $=$ Aboriginal and Torres Strait Islander Health

Bibliography. * These were sorted by study design and include publications that did not sample Indigenous young people.

Indigenous status, included samples that were representative of the target population and employed well defined measures of exposure and outcome (Appendix, 1b; online at mja.com.au). We identified whether descriptive studies reported determinants of health outcomes or health-risk exposures.

\section{Demography: age and location}

We defined three age subgroups (10-14 years, 15-19 years and 20-24 years) and described the source and location (eg, urban, rural) of the study sample as reported in the publication. Most studies did not report the geographical detail necessary for analysis by remoteness index ${ }^{8}$ as we had intended. Instead, we mapped the sample locations from each study manually on an Australian Bureau of Statistics map and compared it with the population distribution of Indigenous Australians, ${ }^{2,19}$ identifying locations using Google Maps Australia (Google Inc). We used the population distribution of all Indigenous Australians as our comparator, as the population distribution of young Indigenous Australians was not available. .,3 $^{2}$

\section{Study focus}

We categorised the focus of each study as either health outcome or health-risk exposure. We further categorised health outcomes using the burden of disease framework as: Group Ia, Communicable diseases; Group Ib, Maternal, perinatal and nutritional conditions; Group II, Non-communicable diseases; and Group III, Injury ${ }^{6,20}$ (Appendix, 2; online at mja.com.au). Health-risk exposures were further categorised using an index of health risks which included the 11 main risk factors defined in the Australian Indigenous burden of disease report, ${ }^{6}$ risk factors as identified by the Global Burden of Disease Study expert group ${ }^{21}$ and risk factors identified for Australian Indigenous children (Appendix, 2). ${ }^{22}$ We included teenage pregnancy as a health-risk exposure as it is a significant social-role transition with implications for individual and population health. ${ }^{23}$ While health outcomes could be categorised against a single burden of disease category, some studies of health risk measured multiple exposures (eg, alcohol and tobacco). We allowed multiple categorisation for studies measuring the 11 key risk factors. Studies measuring 


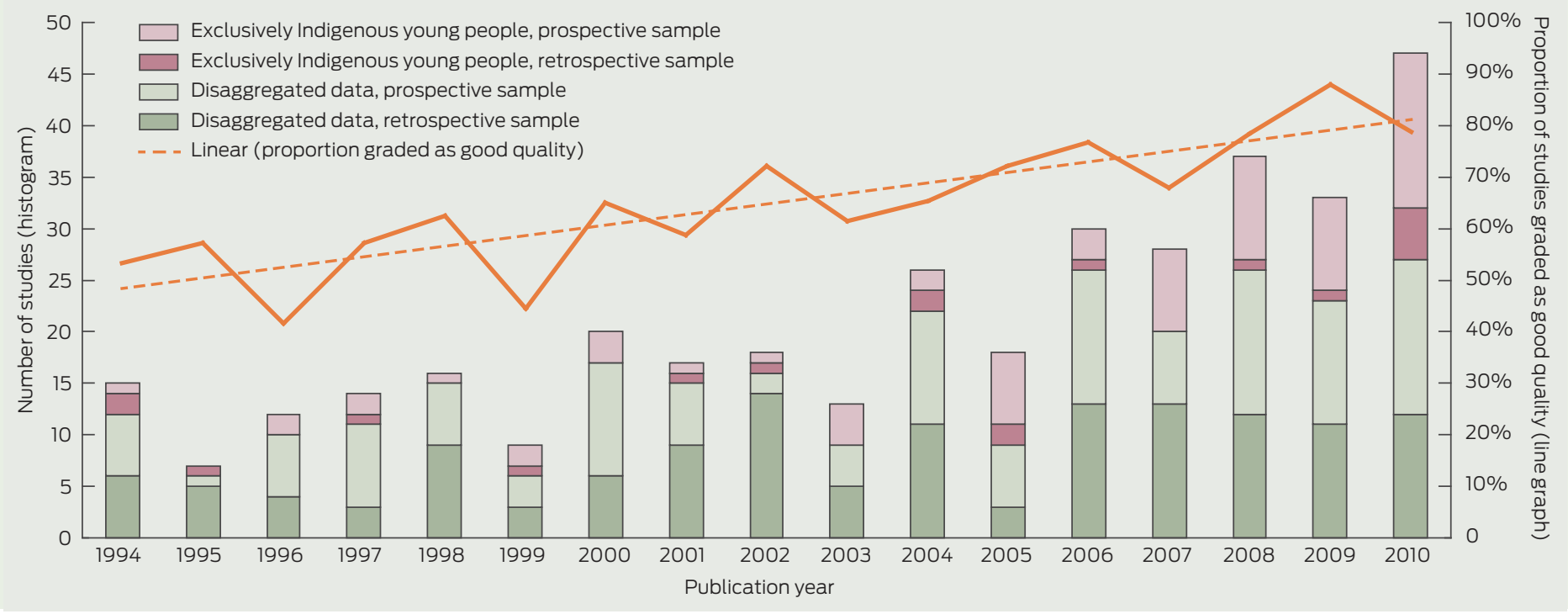

mortality rate (not cause-specific) and population-based studies measuring multiple indicators of health outcome and risk were considered separately.

\section{Data handling and analyses}

The review process was managed using an Excel (Microsoft Corporation) datasheet imported into Stata 10.0 (StataCorp) for analysis. Summary statistics were calculated using the $\chi^{2}$ test and linear and logistic regression. Hierarchical burden of disease groupings were reported using tree maps $^{24}$ generated using the visualisation tool Many Eyes (IBM) and manually traced using Illustrator CS6 (Adobe). The level of statistical significance was set at $P<0.05$.

\section{Results}

Our search strategy identified 3788 citations; 1509 full texts were reviewed, and we identified 360 peer-reviewed studies reporting data for young Indigenous Australians (Box 1). Ninety studies (25.0\%) exclusively sampled Indigenous young people. Two-hundred and two studies (56.1\%) were prospective in design. Studies were mostly descriptive (306 [85.0\%]) and included 14 case series, 37 qualitative studies, 93 surveillance studies, 149 crosssectional studies, 4 case-control studies and 9 cohort studies. Ninety-three of the 306 descriptive studies (30.4\%) reported a determinant. Of the 54 evaluation studies, $34(63.0 \%)$ were quantitative in design and there were no randomised trials. The number of studies published increased over time. The proportion focusing exclusively on Indigenous young people and the proportion with prospective study design increased significantly $(P=0.04$ and $P=0.03$, respectively) (Box 2$)$. While the number of studies evaluating interventions also increased during 1994-2010, the proportion of all studies that were evaluative in design did not change $(P=0.56)$.

\section{Critical appraisal}

Two hundred and fifty studies (69.4\%) were graded as good quality. Data quality improved significantly over time
$(P<0.01)$ (Box 2). Quality was no different for descriptive compared with evaluative design $(P=0.42)$, or according to state or territory of the study sample $(P=0.46)$, urban compared with rural location $(P=0.37)$, study focus $(P=0.18)$ or for studies exclusively sampling Indigenous young people compared with those reporting disaggregated data $(P=0.36)$.

\section{Demography: age and location}

Most studies included young people aged 15-19 years (290 [80.6\%]); 204 studies (56.7\%) included 10-14-year-olds and 141 (39.2\%) included 20-24-year-olds; 173 studies sampled two age subgroups and 51 sampled all three.

Overall, 61 studies (16.9\%) reported data for young people from urban areas, $116(32.2 \%)$ reported data for young people from rural areas, 139 (38.6\%) presented mixed data and $44(12.2 \%)$ studies were unclear. Forty-one of the 61 studies focusing on urban populations were published in 2005-2010 $(P=0.02)$. The community, town or city from which the young people were recruited was clearly identified in 144 studies (40.0\%). Most studies included young people from the Northern Territory, Western Australia and Queensland (Box 3). Compared with studies including disaggregated data, studies that exclusively included Indigenous young people were more likely to have sampled urban populations $(41 \%$ v $25 \% ; P=0.03)$; however, there was no difference by state or territory $(P=$ 0.22 ). Indigenous young people were recruited or data were obtained from communities (113 [31.4\%]), schools (58 [16.1\%]), population datasets (50 [13.9\%]), hospitals $(48,13.3 \%)$, clinics $(47,13.1 \%)$ and correctional facilities (27, $7.5 \%)$. Seventeen studies $(4.7 \%)$ included data from mixed sources.

\section{Study focus}

Overall, 163 (45.3\%) studies focused on health-risk exposures and 197 (54.7\%) focused on outcomes: 65 of these (18.1\%) on communicable diseases, $3(0.8 \%)$ on maternal and nutritional conditions, 97 (26.9\%) on non-communicable diseases, 16 (4.4\%) on injury, and 16 (4.4\%) on noncause-specific mortality or population morbidity. The focus 
3 Sampling of young Indigenous Australians compared with the population distribution of all Indigenous Australians*

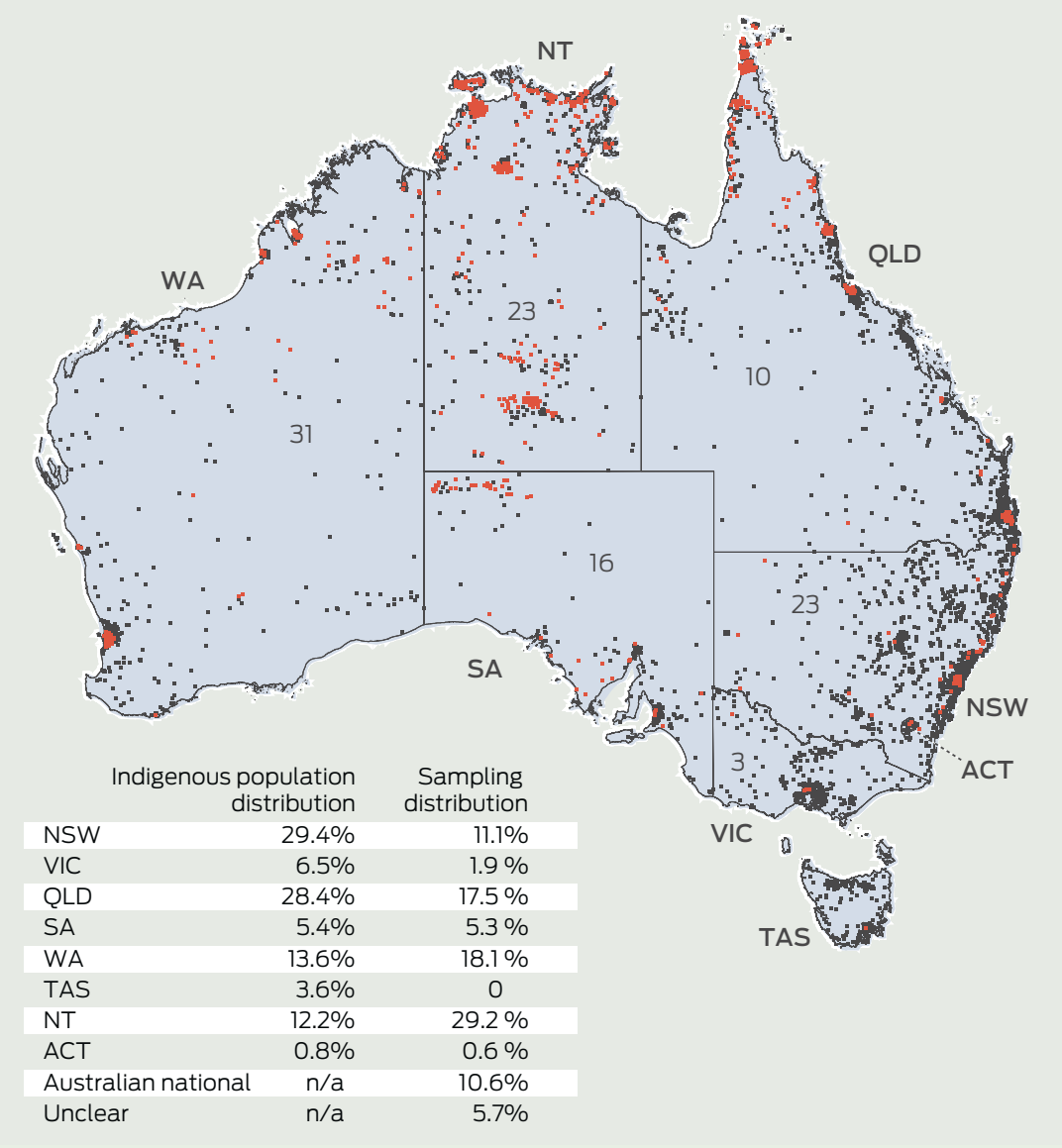

ACT = Australian Capital Territory. NSW $=$ New South Wales. NT = Northern Territory.

$\mathrm{QLD}=$ Queensland. SA = South Australia. TAS = Tasmania. VIC = Victoria. WA = Western Australia.

* The graph shows the population distribution of Indigenous Australians, one dot representing 100

Indigenous Australians. ${ }^{2,19}$ Each red dot represents a single sampling site for a study (studies reporting

sampling from five distinct sites are indicated by five individual dots; studies reporting sample location

at a state or nation level are represented separately by a numeral).

of research did not change during 1994-2010 $(P=0.6)$. Studies that exclusively included Indigenous young people did not focus on injury at all. Study focus did not differ by study quality $(P=0.59)$, and we restricted further analysis to good-quality studies.

Of the 250 good-quality studies, three reported multiple indicators of health for Indigenous young people $\mathrm{e}^{25-27}$ and seven reported mortality (not cause-specific) for the NT, WA, South Australia and Queensland. The remaining 240 good-quality studies included 124 studies of health outcomes (Box 4) and 116 studies of exposure to health risks.

\section{Health outcomes}

The 124 good-quality studies of health outcomes comprised 109 descriptive studies and 15 that evaluated an intervention.

Group Ia: Communicable diseases: Thirty-seven descriptive and eight evaluative studies focused on communicable diseases. Descriptive studies mostly provided prevalence estimates from surveillance studies: 13 provided goodquality data for sexually transmitted infections and nine reported tuberculosis notifications. The eight evaluations focused on testing (4) and treatment (4) approaches.
Group Ib: Maternal, perinatal and nutritional conditions: There was a paucity of data on maternal diseases; one retrospective hospital-based study included some measures of obstetric risk among Indigenous teenage mothers and associated perinatal outcomes and was categorised under health-risk exposure. ${ }^{28}$

Group II: Non-communicable diseases: Fifty-seven descriptive studies and six evaluative studies focused on non-communicable diseases. Eighteen studies focused on mental disorders, nine of these on harmful substance use. Data on depression, anxiety and psychosis were limited. Fifteen descriptive studies focused on oral health; however, we did not identify any studies evaluating interventions. Four studies focused on cardiovascular disease (all on rheumatic heart disease), including a study on mortality. ${ }^{29}$ One study measured mortality related to cervical cancer. ${ }^{30}$

Group III: Injury: Thirteen descriptive studies focused on injury, and included three descriptive studies of suicide and one study of fatal unintentional injury. ${ }^{31-34}$ One study evaluated a community project to address both intentional and unintentional injury. ${ }^{35}$

\section{Health-risk exposures}

The 116 good-quality studies of health-risk exposures comprised 90 descriptive studies and 26 that evaluated an intervention. Eleven studies focused on nutrition and lifestyle, 11 on social-emotional wellbeing, eight on education and nine on justice. Twenty studies focused on sexual and reproductive health, including nine studies of adolescent pregnancy and 11 of related perinatal outcomes. Ten studies focused on health access and included four evaluations. A further eight studies focused on housing, community or parenting. Thirty-nine studies focused on the 11 key risk factors, with eight of these focused on more than one risk factor (Box 5). There were good data for substance use, and while data for unsafe sex were limited, two studies evaluated interventions. ${ }^{36,37}$

\section{Discussion}

Most health-outcome data for Indigenous young people published during 1994-2010 focused on communicable diseases, oral health and substance use. There were also some good-quality data for health-risk exposures related to adult non-communicable diseases (such as substance use, physical activity and diet) and for adolescent pregnancy, including some data on perinatal outcomes. These data illustrate how the health of today's Indigenous young people will affect the health of Indigenous Australian adults and their children in the years to come. The quality of data improved over time, but there were still some important gaps. Data for urban locations were limited, as were data for mental disorders and injury. Data on the health of adolescent mothers were limited, despite fertility peaking in this age group. ${ }^{4}$ Mortality data were not available for all jurisdictions of Australia, and cause-specific estimates were limited. Overall, there was also a paucity of evaluation of programs and interventions. Identification of these gaps may assist in considering future research needs. 
4 Tree map plots* of 124 good-quality published studies on health outcomes among Australian Indigenous young people aged 10-24 years, colourcoded by Burden of Disease Framework category

A: Descriptive studies of health outcomes: focus of descriptive studies as proportions of all descriptive studies (109)

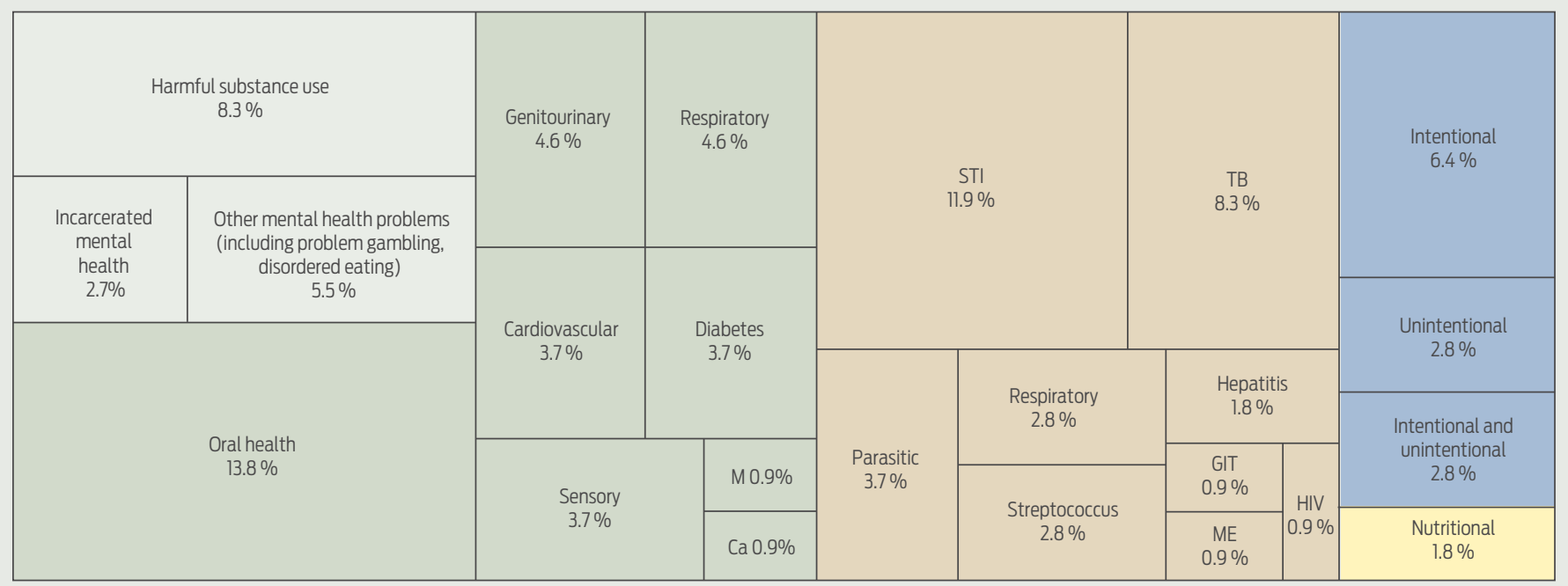

B: Evaluative studies of health outcomes: focus of evaluative studies as proportions of all evaluative studies (15)

\begin{tabular}{|c|c|c|c|c|c|c|}
\hline \multicolumn{2}{|c|}{$\begin{array}{c}\text { Substance use } \\
13.3 \%\end{array}$} & \multirow{2}{*}{$\begin{array}{c}\text { Cardio- } \\
\text { vascular } \\
6.7 \%\end{array}$} & \multirow{2}{*}{$\begin{array}{c}\text { Parasitic } \\
20 \%\end{array}$} & $\begin{array}{c}\text { TB } \\
6.7 \%\end{array}$ & \multirow{2}{*}{$\begin{array}{l}1 \\
n \\
j \\
u \\
r \\
v\end{array}$} & \multirow{2}{*}{$\begin{array}{l}\square \text { la: Communicable diseases } \\
\square \text { lb: Maternal, perinatal and nutritional conditions } \\
\square \text { Il: Non-Communicable diseases }\end{array}$} \\
\hline & & & & $\begin{array}{c}\text { Skin } \\
6.7 \%\end{array}$ & & \\
\hline
\end{tabular}

$\mathrm{M}=$ musculoskeletal. $\mathrm{Ca}$ = malignancy. $\mathrm{GIT}$ = gastrointestinal. $\mathrm{ME}=$ meningoencephalitis. $\mathrm{STI}$ = sexually transmitted infection. $\mathrm{TB}=$ tuberculosis.

\section{Studies of health-risk exposure focusing on 11 key risk factors}

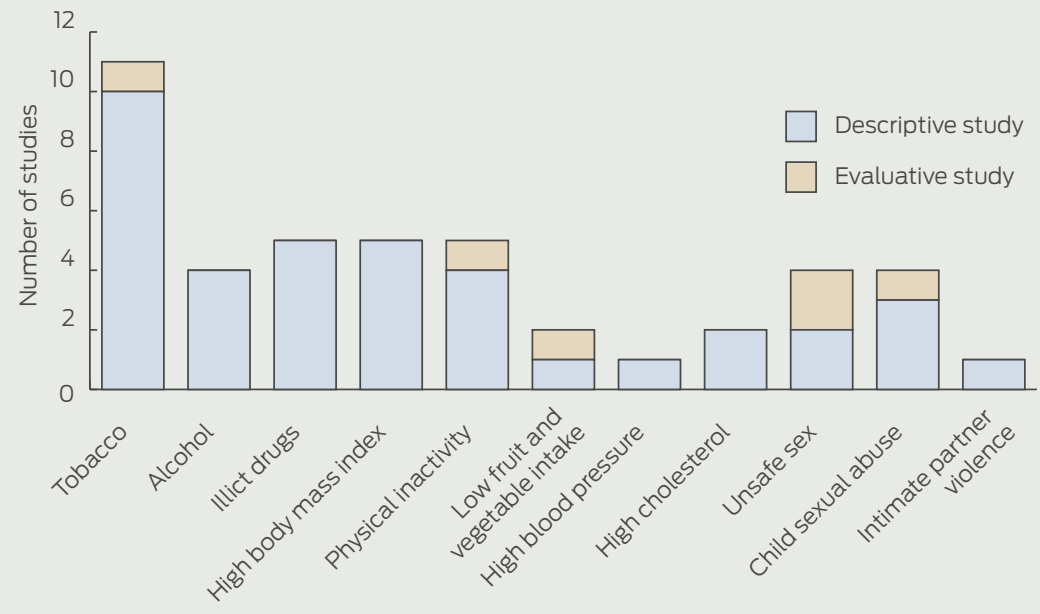

It is important not to interpret these findings as overinvestment of research in some health areas. For example, sexually transmitted infection causes a disproportionate burden of poor health among Indigenous young people, ${ }^{38}$ and relevant good-quality data are likely to have informed the national strategy prioritising control of sexually transmitted infections among Indigenous Australians, particularly young people. ${ }^{39}$

We mapped the focus of studies using the burden of disease framework because using a predefined schedule of health outcome and risk allowed for objective assessment of any data gaps. It is not possible, however, to directly compare the scope of these publications to estimates of the burden of disease among Indigenous young people. Agedisaggregated data allowing calculation of disease burden for 10-24-year-olds were not available. ${ }^{6}$ Furthermore, estimates reported in the Australian Indigenous burden of disease study are dependent on quality input data, largely missing for Indigenous people living in urban settings ${ }^{13}$ and in areas such as mental health. ${ }^{40}$ With these limitations in mind, mental disorders and injury together account for $56 \%$ of the burden of disease among Indigenous people aged 15-34 years (calculated from annex tables). ${ }^{6}$ This proportion is similar for mental disorders and injury in young people aged $10-24$ years globally. ${ }^{41}$ Burden of disease, however, is only one marker of research priority; priorities identified by Indigenous young people and their communities are a fundamental consideration. For example, a qualitative study of Indigenous adolescents in a remote area identified substance use, violence, boredom and racism as significant issues. ${ }^{25}$ Placing the findings of our study in this context, there appears to be a mismatch between estimates of the burden of disease, needs reported by young people, and the focus of research studies in Indigenous young people. The potential for implementing effective (and cost-effective) prevention and intervention is an additional consideration. ${ }^{42}$

The findings of our study are similar to a review of Canadian Indigenous health research that found research 
was primarily focused on health conditions amenable to "curative services". ${ }^{43}$ One possible explanation is that competitive research funding and policy (such as Closing the Gap) encourages investment in health targets that are easily measured and amenable to simple intervention: this is a well recognised challenge of global health policy where there has been acceptable progress towards goals targeting individuals (ie, child survival), while goals such as gender equality and maternal health (shaped by socioeconomic and cultural determinants) have lagged. ${ }^{44,45}$ Despite social determinants playing a central role in Indigenous health inequality, ${ }^{8}$ we identified few studies that focused on social exclusion or socioeconomic inequality (justice, education, employment or housing). Less than a third of descriptive studies measured a determinant.

Three-quarters of all young Indigenous people live in urban and regional areas. ${ }^{3}$ Despite this, overall investment in research involving this population was limited, although it is improving. Challenges of conducting urban Indigenous health research are distinct from the cost and methodological challenges of rural research. ${ }^{46}$ There are no geographical boundaries or readily identifiable target populations that allow identification of Indigenous Australians living in urban settings. ${ }^{13}$ Appropriate consultation and collaboration (essential principles of Indigenous health research) in this context may involve a large number of communities and organisations and requires time, flexibility, and resourcing, ${ }^{47-50}$ which are increasingly at odds with research grants that focus on timely outputs. Developing a robust evidence base may also require non-standard approaches. While Indigenous health research is often conducted in collaboration with Aboriginal communitycontrolled health services or Aboriginal medical services, ${ }^{13}$ the Western Australian Aboriginal Child Health Survey showed that only $12 \%$ of Indigenous 12-17-year-olds had contact with an Aboriginal medical service in the preceding 6 months, with contact lowest among those living in the most urbanised settings. ${ }^{51}$ Data linkage may provide one mechanism to better understand patterns of health and social service access.

Health needs and opportunities for intervention vary significantly across the 10-24-years age band. We did not disaggregate our analysis by age subgroup because almost two-thirds of studies included multiple age subgroups. Additionally, we only included peer-reviewed literature; the grey literature may fill some of the identified gaps. The Western Australian Aboriginal Child Health Survey, for example, is published in four volumes and includes mental health data for 12-17-year-olds. ${ }^{52}$

The findings of our study serve two main purposes. First, we have identified some good-quality literature that can be used to inform health policy and programs to improve the health of young Indigenous Australians; a synthesis of this literature is forthcoming. Second, the findings provide a framework to allow Indigenous communities, researchers, funding bodies and the NHMRC to consider priorities for future research. Marriage of health research to need can only occur with consultation, engagement and the trust of Indigenous communities. This is essential for priority setting, dealing with sensitive health issues (such as mental health, injury and sexual and reproductive health) and appropriately and sustainably engaging young Indigenous Australians in understanding and addressing their health needs. $^{53}$

Acknowledgements: Peter Azzopardi is supported by a National Health and Medical Research Council postgraduate scholarship and Sidney Myer Health Scholarship. We thank Naomi Priest, Senior Research Fellow at the McCaughey VicHealth Centre for Community Wellbeing, Melbourne School of Population and Global Health, for methodological advice based on a review of Australian Indigenous child health.

Competing interests: No relevant disclosures.

1 Sawyer SM, Afifi RA, Bearinger LH, et al. Adolescence: a foundation for future health. Lancet 2012; 379: 1630-1640.

2 Australian Bureau of Statistics. Population characteristics, Aboriginal and Torres Strait Islander Australians, Australia, 2006. Canberra: ABS, 2008. (ABS Cat. No. 4713.0.) http://www.ausstats.abs.gov.au/ausstats/subscriber.nsf/0/ 526FE126443EBCC6CA257718001D547F/\$File/47130_2006_reissue.pdf (accessed Feb 2012).

3 Australian Insitute of Health and Welfare. Young Australians: their health and wellbeing 2011. Canberra: AlHW, 2011. (AlHW Cat. No. PHE 140.) http://www. aihw.gov.au/WorkArea/DownloadAsset.aspx?id=10737419259 (accessed Feb 2012)

4 Australian Bureau of Statistics. Births Australia. 2009. Canberra: ABS, 2010. (ABS Cat. No. 3301.0.) http://www.ausstats.abs.gov.au/ausstats/subscriber nsf/0/10BEDC49AFCACCIFCA2577CF000DF7AB/\$File/33010_2009.pdf (accessed Feb 2012).

5 Paradies Y, Cunningham J. Placing Aboriginal and Torres Strait Islander mortality in an international context. Aust N Z J Public Health 2002; 26: 11-16.

6 Vos T, Barker B, Stanley L, Lopez AD. The burden of disease and injury in Aboriginal and Torres Strait Islander peoples 2003. Brisbane: School of Population Health, University of Queensland, 2007. http://www.lowitja.org. au/sites/default/files/docs/Indigenous-BoD-Report.pdf (accessed Feb 2012).

7 Vos T, Barker B, Begg S, et al. Burden of disease and injury in Aboriginal and Torres Strait Islander peoples: the Indigenous health gap. Int J Epidemiol 2009; 38: 470-477.

8 Council of Australian Governments. National Indigenous Reform Agreement (Closing the Gap). COAG, 2008. http://www.federalfinancialrelations.gov.au/ content/npa/health_indigenous/indigenous-reform/national-agreement sept_12.pdf (accessed Feb 2012).

9 Australian Government. Closing the Gap: Prime Minister's Report 2012. Canberra: Department of Families, Housing, Community Services and Indigenous Affairs, 2012. http://www.fahcsia.gov.au/sites/default/files/ documents/05_2012/closing_the_gap_2012.pdf (accessed Feb 2012).

10 National Aboriginal and Torres Strait Islander Health Equality Council. Indigenous Youth Health and Wellbeing Roundtable outcomes: December 2009 (draft report). Canberra: NATSIHEC, 2009.

11 Patton GC, Coffey C, Cappa C, et al. Health of the world's adolescents: a synthesis of internationally comparable data. Lancet 2012; 379: 1665-1675.

12 Huppatz C. "Sorry" - in word and actions. Improving health in rural and remote Indigenous communities. Rural Remote Health 2008; 8: 876.

13 Eades SJ, Taylor B, Bailey S, et al. The health of urban Aboriginal people: insufficient data to close the gap. Med J Aust 2010; 193: 521-524.

14 Paul CL, Sanson-Fisher R, Stewart J, Anderson AE. Being sorry is not enough: the sorry state of the evidence base for improving the health of indigenous populations. Am J Prev Med 2010; 38: 566-568.

15 Australian Government National Health and Medical Research Council. The NHMRC road map: a strategic framework for improving Aboriginal and Torres Strait Islander health through research. Canberra: Aboriginal and Torres Strait Islander Research Agenda Working Group of the NHMRC, 2002. http://www. nhmrc.gov.au/_files_nhmrc/publications/attachments/r28.pdf (accessed Sep 2011).

16 de la Barra SL, Redman S, Eades S. Health research policy: a case study of policy change in Aboriginal and Torres Strait Islander health research. Aust New Zealand Health Policy 2009; 6: 2.

17 Sanson-Fisher RW, Campbell EM, Perkins JJ, et al. Indigenous health research: a critical review of outputs over time. Med J Aust 2006; 184: 502-505.

18 National Centre for Social Applications of GIS (GISCA). ARIA and accessibility. http://www.adelaide.edu.au/apmrc/research/projects/category/aria.html (accessed Jun 2013).

19 Australian Government. Closing the Gap: Prime Minister's Report 2010. Canberra: Commonwealth of Australia, 2010. http://www.fahcsia.gov.au/ sites/default/files/documents/05_2012/closingthegap2010_1.pdf (accessed Jun 2013).

20 World Health Organization. The global burden of disease: 2004 update. Geneva:WHO, 2008. http://www.who.int/healthinfo/global_burden_disease/ GBD_report_2004update_full.pdf (accessed Feb 2012).

21 University of New South Wales, Global Burden of Disease: Mental Disorders and Illicit Drug Use Expert Group. Diseases and risks. Sydney: National Drug and Alcohol Research Centre, UNSW. http://www.gbd.unsw.edu.au/ gbdweb.nsf/page/Diseases+and+Risks (accessed Jul 2010).

22 Priest N, Mackean T, Waters E, et al. Indigenous child health research: a critical analysis of Australian studies. Aust N Z J Public Health 2009; 33: 55-63. 
23 World Health Organization. Adolescent pregnancy - unmet needs and undone deeds. A review of the literature and programmes. Geneva: WHO Department of Child and Adolescent Health and Development, 2007. http:// whqlibdoc.who.int/publications/2007/9789241595650_eng.pdf (accessed Feb 2012).

24 McConnell P, Johnson K, Lin S. Applications of tree-maps to hierarchical biological data. Bioinformatics 2002; 18: 1278-1279.

25 Mohajer N, Bessarab D, Earnest J. There should be more help out here! A qualitative study of the needs of Aboriginal adolescents in rural Australia. Rural Remote Health 2009; 9: 1137.

26 Silburn SR, Blair E, Griffin JA, et al. Developmental and environmental factors supporting the health and well-being of Aboriginal adolescents. Int J Adolesc Med Health 2007; 19: 345-354.

27 Blair EM, Zubrick SR, Cox AH. The Western Australian Aboriginal Child Health Survey: findings to date on adolescents. Med J Aust 2005; 183: 433-435.

28 Lewis LN, Hickey M, Doherty DA, Skinner SR. How do pregnancy outcomes differ in teenage mothers? A Western Australian study. Med J Aust 2009; 190: 537-541.

29 Carapetis JR, Currie BJ. Mortality due to acute rheumatic fever and rheumatic heart disease in the Northern Territory: a preventable cause of death in Aboriginal people. Aust N Z J Public Health 1999; 23: 159-163.

30 O'Brien ED, Bailie RS, Jelfs PL. Cervical cancer mortality in Australia: contrasting risk by aboriginality, age and rurality. Int J Epidemiol 2000; 29: 813-816.

31 Measey M-AL, Li SQ, Parker R, Wang Z. Suicide in the Northern Territory, 1981-2002. Med J Aust 2006; 185: 315-319.

32 Clapham KF, Stevenson MR, Lo SK. Injury profiles of Indigenous and nonIndigenous people in New South Wales. Med J Aust 2006; 184: 217-220.

33 Pridmore S, Fujiyama H. Suicide in the Northern Territory, 2001-2006. Aust NZ J Psychiatry 2009; 43: 1126-1130.

34 Rock DJ, Hallmayer JF. The seasonal risk for deliberate self-harm. Determined by place of birth, but occurrence determined by place of residence. Crisis 2008; 29: 191-201.

35 Shannon C, Canuto C, Young E, et al. Injury prevention in Indigenous communities: results of a two-year community development project. Health Promot J Aust 2001; 12: 233-237.

36 Rayne C, Molloy R, Greet B. Indigenous youth deliver sexual health message. Aboriginal and Islander Health Worker Journal 2005; 29 (2): 9-11.

37 Mikhailovich K, Arabena K. Evaluating an indigenous sexual health peer education project. Health Promot J Aust 2005; 16: 189-193.

38 Fairley CK, Hocking JS. Sexual health in Indigenous communities [editorial]. Med J Aust 2012; 197: 597-598.

39 Australian Government Department of Health and Ageing. Third National Aboriginal and Torres Strait Islander Blood Borne Viruses and Sexually Transmissible Infections Strategy, 2010-2013. Canberra: Commonwealth of Australia, 2010. http://www.health.gov.au/internet/main/publishing.nsf/ Content/8AFCF786E7C15CFECA2577190002862A/\$File/atsi.pdf (accessed Feb 2012)
40 Jorm AF, Bourchier SJ, Cvetkovski S, Stewart G. Mental health of Indigenous Australians: a review of findings from community surveys. Med J Aust 2012; 196: 118-121.

41 Gore FM, Bloem PJ, Patton GC, et al. Global burden of disease in young people aged 10-24 years: a systematic analysis. Lancet 2011; 377: 2093-2102.

42 Vos T, Carter R, Barendregt J, et al; ACE-Prevention Team. Assessing CostEffectiveness in Prevention (ACE-Prevention): final report. University of Queensland, Brisbane and Deakin University, Melbourne, 2010. http:// www.sph.uq.edu.au/docs/BODCE/ACE-P/ACE-Prevention_final_report.pdf (accessed Feb 2012).

43 Young TK. Review of research on aboriginal populations in Canada: relevance to their health needs. BMJ 2003; 327: 419-422.

44 Wagstaff A, Claeson M. The Millenium Development Goals for health: rising to the challenges. Washington, DC: World Bank, 2004. http://www.afro.who.int/ index.php?option=com_docman\&task=doc_download\&gid=2354 (accessed Feb 2012).

45 United Nations. The Millenium Development Goals Report 2012. New York, NY: United Nations, 2012. http://mdgs.un.org/unsd/mdg/Resources/Static/ Products/Progress2012/English2012.pdf (accessed Oct 2012).

46 Clough AR. Some costs and challenges of conducting follow-up studies of substance use in remote Aboriginal communities: an example from the Northern Territory. Drug Alcohol Rev 2006; 25: 455-458.

47 Onemda VicHealth Koori Health Unit. We can like research ... in Koori hands: a community report on Onemda VicHealth Koori Health Unit's research workshops in 2007. Melbourne: Onemda VicHealth Koori Health Unit, University of Melbourne, 2008. http://www.onemda.unimelb.edu.au/sites/ default/files/docs/In Koori Hands_FINAL.pdf (accessed Feb 2012).

48 Laycock A, Walker D, Harrison N, Brands J. Researching Indigenous health a practical guide for researchers. Melbourne: Lowitja Institute, 2011.

49 Jamieson LM, Paradies YC, Eades S, et al. Ten principles relevant to health research among Indigenous Australian populations. Med J Aust 2012; 197: $16-18$.

50 Holmes W, Stewart P, Garrow A, et al. Researching Aboriginal health: experience from a study of urban young people's health and well-being. Soc Sci Med 2002; 54: 1267-1279.

51 Zubrick SR, Lawrence DM, Silburn SR, et al. The Western Australian Aboriginal Child Health Survey, vol. 1. The health of Aboriginal children and young people. Perth: Telethon Institute for Child Health Research, 2004. http:// aboriginal.childhealthresearch.org.au/kulunga-research-network/ waachs.aspx (accessed Feb 2012).

52 Zubrick SR, Silburn SR, Lawrence DM, et al. The Western Australian Aboriginal Child Health Survey, vol. 2. The social and emotional wellbeing of Aboriginal children and young people. Perth: Curtin University of Technology and Telethon Institute for Child Health Research, 2005. http:// aboriginal.childhealthresearch.org.au/kulunga-research-network/waachs/ waachs-volume-2.aspx (accessed Feb 2012).

53 Mentha RA, de Vries J, Simon PR, et al. Bringing our voices into the research world: lessons from the Kanyini Vascular Collaboration. Med J Aust 2012; 197: 55-56. 